\title{
Chlorophyll Concentration and Morphological Diversity in Corn Lines at Different Vegetative Stages
}

\author{
Mariano Mendoza Elos' ${ }^{1}$, Gilberto Rodríguez Pérez ${ }^{*}$, \\ Francisco Cervantes Ortíz ${ }^{1}$, Luis Patricio Guevara Acevedo ${ }^{1}$, \\ Enrique Andrio Enríquez', Ma. Del Carmen Ojeda Zacarías', \\ Isabel Presa Figuereo', Sergio Alfredo Rodríguez Herrera ${ }^{3}$, \\ José Antonio Rangel Lucio' ${ }^{1}$, José Guadalupe Rivera Reyes ${ }^{1}$ \\ ${ }^{1}$ Division of Graduate Studies and Research, Institute Technologic of Roque, Guanajuato, México \\ ${ }^{2}$ University Autonomous Agrarian of Nuevo León, Monterrey, México \\ ${ }^{3}$ University Autonomous Agrarian Antonio Narro, Saltillo, México \\ Email: "grodriguez263@hotmail.com
}

Received 6 February 2016; accepted 15 May 2016; published 18 May 2016

Copyright (C) 2016 by authors and Scientific Research Publishing Inc.

This work is licensed under the Creative Commons Attribution International License (CC BY). http://creativecommons.org/licenses/by/4.0/

(c) (i) Open Access

\section{Abstract}

The objective of this study was to assess the chlorophyll content of corn lines at different vegetative stages and the diversity between them. The study was conducted in the experimental field of the Roque Institute of Technology (ITR) located in Roque, Celaya, Guanajuato, Mexico. We used 32 corn lines from CIMMYT and four lines from the breeding program of the ITR. The evaluation was conducted in the spring-summer cycle of 2014 at two planting dates. We used a completely randomized block design with three replications. The experimental unit consisted of two rows of five linear meters with a distance of 0.75 meters between rows. Chlorophyll was measured at six different stages: V6, VT, R3, R4, R5 and MF. The agronomic variables recorded were: PH, CH, LAC, LBC, FF, MF, PM, CC, CL, DC, RC, KR and GY. The results of the analysis of variance showed significant differences between lines, dates and their interaction. On average, 18 lines were found with chlorophyll concentrations above 51 SPAD units in the two environments. This indicated that these materials had a high potential for field performance. Using cluster analysis UPGMA method, we identified seven groups for chlorophyll and eight groups for agronomic characteristics for a breeding program. The groups were associated to the homogeneous characteristics of each variable.

\footnotetext{
${ }^{*}$ Corresponding author.
} 
Keywords

\section{Chlorophyll Content, Phenological Stages, Clusters and Corn Lines}

\section{Introduction}

Maize (Zea mays L.) is one of the most important cereal crops world-wide as well as an important source of feed, fibre, and biofuel. Potassium (K) as one of the essential nutrients for crop plays an important role in crop growth and development, metabolism and yield formation process [1] [2]. Because of long-term agricultural production of existing cultivated land, there is about $60 \%$ of massive arable land potassium deficiency, which inhibit crop yield and quality improvement [3] [4]. The leaf senescence shortens the duration of the photosynthesis after heading, and reduces the photosynthetic production accumulation [5] [6]. Potassium deficiency in plants usually induces brown scorching and curling of leaf tips as well as chlorosis (yellowing) between leaf veins, which accelerate leaf senescence. Leaf photosynthesis consists of the several physiological processes, including light harvesting, photosystem II (PSII) photochemistry and CO2 assimilation [7]. Chlorophyll fluorescence measurements have increasingly been used as a non-invasive tool in leaf ecophysiological studies. This method has been used extensively to investigate the response of plants to environmental stress, including the effects of low potassium on the photosynthetic apparatus of crops both in a controlled environment and in the field [8] [9].

It has been known for years that corn requires large quantities of nitrogen $(\mathrm{N})$, and that the fraction of nitrogen recovered is low, typically less than 50\% [10]. In Chile, the most recent estimates of the efficiency of nitrogen use in corn range from $27 \%$ to $38 \%$ [11]. Moreover, the increasing need to reduce costs, improve efficiency in the use of nitrogen fertilizers and prevent nitrate pollution, requires the use of new tools for measuring the nutritional status of crops, especially if this can be done by non-destructive methods. The ideal solution will be to keep track of leaf nitrogen levels during the period of crop development, making it possible to correct deficiencies and improve crop yields.

One way to determine foliar nitrogen quickly is by using a Minolta ${ }^{\circledR}$ Chlorophyll Meter SPAD 502 (Soil Plant Análisis Development) to measure the greenness index, which is directly related to the content of chlorophyll in the leaves of the plants. This portable equipment allows an indirect and non-destructive assessment of leaf chlorophyll content by measuring the light transmitted through the leaf at $650 \mathrm{~nm}$ and $940 \mathrm{~nm}$. Its use has been successful in terms of assessing the nutritional status of nitrogen in several crops [12] [13]. Plants are so effective at producing energy that they can produce enough energy to grow and reproduce [14]. The author also points out that not all plants produce the same amount of energy, since it depends, on the one hand, on environmental conditions such as light, temperature, humidity, atmospheric gases, etc. and, on the other, on the type of plants. Corn has a high yield potential associated with efficient photosynthetic mechanisms; its maximum rate is 50 to $60 \mathrm{mg}$ of $\mathrm{CO}_{2} \mathrm{dm}^{-2} \cdot \mathrm{h}^{-1}$, with an optimal temperature between $35^{\circ} \mathrm{C}$ and $40^{\circ} \mathrm{C}$ [15]. The growth and yield of plants are closely related to environmental factors and crop management. The quantity, quality and duration of light and temperature, as well as the date and density of planting, soil moisture and chemical fertilization, particularly with nitrogen, affect the concentration of chlorophyll, the formation of biomass and grain yield. Chlorophyll is the primary photosynthetic pigment of plants; together with foliar nitrogen, it varies with solar radiation [16]. Leaf chlorophyll is closely related to the concentration of $\mathrm{N}$, reflecting the nutritional status of the plant with respect to this important nutrient. Nitrogen is essential for the synthesis of chlorophyll; as part of this molecule, it is involved in the process of photosynthesis [17] Potash and Phosphate Institute, 1997. Adequate amounts of nitrogen in the plant produce dark green leaves with a high concentration of chlorophyll. The green pigment of chlorophyll absorbs the light energy needed to start photosynthesis. The objective of this research was to determine chlorophyll concentration and yield response in elite corn lines with low level of inbreeding in the Bajío region of Mexico.

The analysis of the diversity within and between corn lines, populations and hybrids, has been based on the evaluation of their morphological differences. This has the advantage that morphological differences are easily measurable, do not require sophisticated equipment and are the most direct way of assessing a phenotype. However, the morphological analysis must be performed by an expert, as the components are subject to change due to environmental factors and may vary at different stages of plant development. Like other species, corn has developed morphological adaptations in response to the environmental conditions where it grows. These adapta- 
tions manifest as changes in plant height, corn cob height, the number, size and angle of leaves, the number of branches of the ear, corn cob length [18] (Rodriguez et al., 2012).

\section{Material and Methods}

\subsection{Plant Materials and Experimental Design}

The study was conducted in the experimental field of the Division of Graduate Studies and Research of the Roque Institute of Technology (ITR), located at kilometer 8 of the Celaya-Juventino Rosas highway in Celaya, Guanajuato, with coordinates $20^{\circ} 34^{\prime} 54.24 " \mathrm{~N}$ and $100^{\circ} 49^{\prime} 35.34^{\prime \prime} \mathrm{W}$ and an altitude of 1767 masl [10] (INEGI, 2014). The climate is semi-warm, sub-humid BS, and $\mathrm{C}$ (Wo), with the average temperature ranging from $14^{\circ} \mathrm{C}$ to $22^{\circ} \mathrm{C}$, and rainfall ranging from $600-1000$ milliliters per year. The soils in the region are PelicVertisol and Chromic Vertisol, with predominance of the first. These soils are clayey, slightly alkaline levels, extremely fertile and suitable to a variety of crops. We used 36 corn inbred lines (S9) and a randomized complete block design with three replications. The experimental plot consisted of two furrows $5 \mathrm{~m}$ in length and $0.75 \mathrm{~m}$ apart, with a plant spacing of $17 \mathrm{~cm}$, giving a population density of 85,000 plants per hectare. The experiment was established in two planting dates, the first on March 31, and the second on June 4. Planting was done manually, planting two seeds per hole at a distance of $0.25 \mathrm{~m}$. The material was planted in moist soil and the first irrigation was applied at 15 days. The fertilizer formula was 240-60-00 (NPK); it was applied in two doses, the first at 35 days after planting, and the second at 75 days. We used 32 elite lines from the International Maize and Wheat Improvement Center (CIMMYT), and four lines from the improvement program of the ITR (Table 1).

\subsection{Treatment}

We determined chlorophyll concentration at six stages (Table 2) using a chlorophyll meter SPAD-502 (Minolta Camera Co., Ltd., Japan). Chlorophyll concentration was measured at the following stages: V6, considering the last true leaf, VT, R3, R4, R5 and physiological maturity; in the latter stages, we considered the leaf of the main cob and performed three measurements per leaf (basal, middle and apical). The values were recorded in SPAD units. We performed a combined analysis, considering lines and dates, using the SAS software v.9.3; Tukey's test was used to compare the means (5\%). We performed a morphological characterization of the 36 corn lines, of which 32 were from CIMMYT and four from the ITR; this was done in order to determine the similarities and differences between them, and to identify common groups that allow for more efficient breeding. In this characterization, we measured the following variables: plant height $(\mathrm{PH})$, measured from the base of the plant to the tip of the ear; corn cob height $(\mathrm{CH})$, measured from the base of the plant to the base of the cob; days to male flowering (MF), established as the day when more than $50 \%$ of the plants in the plot were releasing pollen on more than $50 \%$ of the ear; days to female flowering (FF), established as the day when more than $50 \%$ of the plants in the plot had receptive stigmas; leaves below the corn cob (LBC); leaves above the corn cob (LAC); corn cob cover (CC); corn cob length (CL), measured with a ruler graduated in $\mathrm{cm}$, from the base to the tip of the corn cob, in a sample of five corn cobs per plot; diameter of the cob (DC), measured in the middle of the cob with a vernier graduated in $\mathrm{cm}$, recording the average of five cobs per plot; number of rows per cob (RC) and kernels per row (KR), estimated by counting the rows and the number of grains per row in a sample of five cobs per plot and recording the average value; physiological maturity (PM), defined as the days from the first irrigation day; and grain yield (GY), estimated by harvesting all plants in the plot, weighing the grain in $\mathrm{kg}$, and calculating $t \cdot h a^{-1}$ adjusted to $15 \%$ moisture. For the identification and selection of the lines, we built a matrix with the average values of the 14 agronomic characteristics from the three repetitions and the two dates, in order to generate a dendrogram by cluster analysis; the $\mathrm{x}$-axis represented the Euclidean distances between genetic links, and the y-axis represented the corn lines. We used the UPGMA method (Unweighted Pair-Group Method with Arithmetic mean) to calculate the distances and generate compact and homogeneous groups in order to morphologically differentiate the groups within the lines.

\subsection{Clusters of Lines}

These groups allowed us to observe the grouping tendency of the 36 lines. The UPGMA method associates the lines to find closely related groups based on the Euclidean distances matrix; it calculates a distance matrix and repeats the process until all the lines are associated to a single group. The strategy computes the average distance 
Table 1. Genealogical description of the lines.

\begin{tabular}{|c|c|c|c|c|}
\hline Line & Origin & Environment & Maturity & Grain Color \\
\hline CML 144 & CIMMYT & tropical & late & white \\
\hline CML 159 & CIMMYT & tropical & late & white \\
\hline CML 161 & CIMMYT & tropical & late & yellow \\
\hline CML 163 & CIMMYT & tropical & late & yellow \\
\hline CML 176 & CIMMYT & subtropical & intermediate & white \\
\hline CML 197 & CIMMYT & subtropical & late & white \\
\hline CML 202 & CIMMYT & subtropical & late & white \\
\hline CML 206 & CIMMYT & subtropical & late & white \\
\hline CML 216 & CIMMYT & subtropical & late & white \\
\hline CML 247 & CIMMYT & tropical & late & white \\
\hline CML 251 & CIMMYT & tropical & intermediate & white \\
\hline CML 254 & CIMMYT & tropical & intermediate & white \\
\hline CML 264 & CIMMYT & tropical & intermediate & white \\
\hline CML 287 & CIMMYT & tropical & intermediate & yellow \\
\hline CML 311 & CIMMYT & subtropical & late & white \\
\hline CML 312 & CIMMYT & subtropical & intermediate & white \\
\hline CML 376 & CIMMYT & subtropical & intermediate & white \\
\hline CML 387 & CIMMYT & subtropical & late & white \\
\hline CML 395 & CIMMYT & subtropical & late & white \\
\hline CML 421 & CIMMYT & tropical & early & yellow \\
\hline CML 444 & CIMMYT & subtropical & late & white \\
\hline CML 448 & CIMMYT & tropical & late & yellow \\
\hline CML 451 & CIMMYT & tropical & late & yellow \\
\hline CML 456 & CIMMYT & highvalleys & intermediate & white \\
\hline CML 465 & CIMMYT & tropical & late & yellow \\
\hline CML 470 & CIMMYT & tropical & early & yellow \\
\hline CML 491 & CIMMYT & tropical & late & white \\
\hline CML 496 & CIMMYT & tropical & intermediate & yellow \\
\hline CML 504 & CIMMYT & tropical & intermediate & white \\
\hline CML 505 & CIMMYT & tropical & intermediate & white \\
\hline CML 509 & CIMMYT & tropical & intermediate & white \\
\hline CML 511 & CIMMYT & tropical & intermediate & white \\
\hline TNM 6 & ITR & subtropical & intermediate & white \\
\hline TNM 7 & ITR & subtropical & intermediate & white \\
\hline TNM 8 & ITR & subtropical & intermediate & white \\
\hline TNM 9 & ITR & subtropical & intermediate & white \\
\hline
\end{tabular}


Table 2. Phenological stages of the corn lines; Roque, Celaya, Guanajuato, 2014.

\begin{tabular}{cccc}
\hline Measurement & Stage & Days & Description \\
\hline 1 & V6 & 40 & The collar of the sixth leaf is visible \\
2 & VT & 87 & Flowering \\
3 & R3 & 97 & Milky stage \\
4 & R4 & 107 & Doughystage \\
5 & R5 & 117 & Dentedstage \\
6 & MF & 127 & Physiologicalmaturity \\
\hline
\end{tabular}

to form a grouping (i j). This process uses the distances of all population pairs in the dendrogram (ni, nj); the distances between the group ( $\mathrm{i}$ j) and another dendrogram $\mathrm{H}$ is obtained by:

$$
\mathrm{D}(\mathrm{ij}) \mathrm{H}=\frac{\dot{\mathrm{a}}_{\mathrm{i}} \dot{\mathrm{a}}_{\mathrm{k}} \mathrm{Dik}}{\mathrm{N}(\mathrm{K}) \mathrm{N}(\mathrm{H})}
$$

where: Dik = distance between lines in the dendrogram ( $\mathrm{i} j$ ) and lines in the dendrogram $\mathrm{H}$.

$\mathrm{N}(\mathrm{K}) \mathrm{N}(\mathrm{H})=$ number of data in dendrograms $(\mathrm{i} \mathrm{j})$ and $\mathrm{H}$, respectively.

The parameters used by the combinatorial formula are: $\alpha \mathrm{i}=\alpha \mathrm{j}=-0.5$ (Everitt, 1980; Lance and Williams, 1967).

\section{Results and Discussion}

\section{Statistical Analysis}

Table 3 shows the mean squares of the chlorophyll measurements at six the development stages. It is possible to observe statistical differences $(\mathrm{p} \leq 0.01)$ between lines and dates in the six stages, indicating that there is wide variability between corn lines, which exhibited different responses between dates. These results could be due to the influence of weather conditions such as rainfall, temperature and solar energy on plant behavior [19]. There were significant differences $(\mathrm{p} \leq 0.05)$ in the interaction between the V6, R3, R5 and MF stages. With regard to the comparison of means (Tukey, 0.05), the averages are presented in Table 4. The lines with highest content of chlorophyll in the V6 stage were CML 312, CML 376, CML 197, CML 311 and CML 421; in the flowering stage (VT), the lines with highest values of chlorophyll were CML 197, CML 312, CML 387, CML 202 and CML 491; in the case of the reproductive stage (R3), the lines in the first statistical group were CML 387, CML 197, CML 251, CML 247 and CML 496. There was a difference in SPAD units between the development stages, except for the V6 and VT stages; the R3 stage had the highest concentration of chlorophyll after 97 days, with a value greater than 59.91 SPAD units. The CML 312 line had the highest concentration of chlorophyll in the first statistical group. These results do not coincide with those reported by [20], who reported chlorophyll values above 55, suggested that an adequate concentration of chlorophyll to obtain good corn yields should be above 51 SPAD units. They also mentioned that a value of 35.3 SPAD units is considered critical for corn, and is equivalent to $1.83 \%$ of nitrogen in the plant; in the present study, we found higher SPAD values. The results indicate that March provided the best environment for the corn lines, as it was then that they had the highest chlorophyll content. In the reproductive stages R4, R5 and MF, the highest values were: 53.72, 54.15 and 41.38 SPAD units, respectively. The maturation of the lines was not consistent in the chlorophyll records; although we noted that an increase in chlorophyll concentration after 107 days corresponded to stage R4, only the CML107 and CML212 lines had high SPAD values of 53.72 and 51.37, respectively, which would allow to obtain good yields, considering the data reported by [21]. Moreover, we noted that the CML197 line had its highest value, 54.15, at 117 days (stage R5); however, the chlorophyll concentration decreased at 127 days (MF). Thus, the lines with an average SPAD value above 51 units have the greatest potential, which is reflected in the fact that the best yields were obtained between 107 and 117 days. This behavior is consistent with the data obtained by [22], who reported that the highest content of chlorophyll was found in the cob leaf when it was in the doughy stage. With regard to planting dates, the results indicate that an early date (March) provides the most optimal environment, 
Table 3. Mean squares of chlorophyll (SPAD units) at the different phenological stages of the corn lines. Roque, Celaya, Guanajuato, 2014.

\begin{tabular}{cccccccc}
\hline FV & GL & V6 & VT & R3 & R4 & R5 & MF \\
\hline Blocks & 2 & 6.09 & 24.94 & 14.31 & 7.94 & 249.09 & 43.60 \\
Lines (A) & 35 & $65.68^{* *}$ & $76.92^{* *}$ & $116.62^{* *}$ & $171.41^{* *}$ & $231.58^{* *}$ & $223.01^{* *}$ \\
Dates (B) & 1 & $333.01^{* *}$ & $2238.00^{* *}$ & $1952.89^{* *}$ & $3405.00^{* *}$ & $4346.00^{* *}$ & $15,471.98^{* *}$ \\
A x B & 35 & $40.86^{*}$ & $27.35^{\text {ns }}$ & $60.09^{*}$ & $38.58^{\text {ns }}$ & $94.00^{*}$ & $111.68^{*}$ \\
Error & 70 & 23.09 & 23.04 & 34.11 & 34.39 & 52.85 & 69.86 \\
Total & 215 & 7541.60 & 9753.10 & 13044.81 & 15271.73 & $2,3655.37$ & $38,131.82$ \\
\hline
\end{tabular}

${ }^{* *}=$ significance at $\mathrm{p}<0.01 ;{ }^{*}=$ significance at $\mathrm{p}<0.05 ; \mathrm{ns}=$ not significant. V6 = sixth leaf stage. VT = flowering stage. R3 = milk stage. R4 = doughy stage. $\mathrm{R} 5$ = dented stage and PM = physiological maturity.

Table 4. Comparison of the means of chlorophyll content (SPAD units) in the combined analysis of different phenological stages of corn lines. Roque. Celaya, Guanajuato, 2014.

\begin{tabular}{|c|c|c|c|c|c|c|}
\hline Line & V6 & VT & R3 & $\mathrm{R} 4$ & R5 & $\mathrm{MF}$ \\
\hline CML312 & $57.6 \mathrm{a}$ & $55.2 \mathrm{ab}$ & 49.4abc & $51.2 \mathrm{ab}$ & 39.6abcd & 31.5abc \\
\hline CML376 & 54.7ab & 48.1abc & 44.33bc & 43.2abcdefg & 39.6abcd & 24.9abc \\
\hline CML197 & 54.6ab & $58.4 \mathrm{a}$ & $56.2 \mathrm{a}$ & $53.7 \mathrm{a}$ & 54.1ab & $41.3 \mathrm{a}$ \\
\hline CML311 & 53.8ab & 47.7abc & 47.6abc & 38.1bcdefg & 34.5abc & 28.6abc \\
\hline CML421 & 53.8ab & 51.3ab & 43.9bc & 38.5bcdefg & $25.3 d$ & $12.5 \mathrm{c}$ \\
\hline CML456 & 53.8ab & 53.3ab & 49.9abc & 40.3abcdefg & 33.5abc & 28.7abc \\
\hline CML491 & $52.0 \mathrm{ab}$ & $54.5 \mathrm{ab}$ & 46.3ab & 47.8abcde & 46.9ab & $39.4 \mathrm{a} 7$ \\
\hline TNM 8 & $52.9 \mathrm{ab}$ & 51.3ab & 48.03abc & 47.5abcde & 47.8ab & 30.3abc \\
\hline CML159 & $52.6 \mathrm{ab}$ & $46.5 b c$ & 47.53abc & 43.7abcdefg & 32.75abc & $20.0 \mathrm{bc}$ \\
\hline CML505 & $52.5 \mathrm{ab}$ & $53.5 \mathrm{ab}$ & 49.6abc & 44.9abcdef & 37.8abcd & 28.5abc \\
\hline CML287 & $52.5 a b$ & 49.0abc & $44.6 \mathrm{bc}$ & 33.3g & 29.8dc & 23.1abc \\
\hline CML496 & 52.3ab & $52.0 \mathrm{ab}$ & 53.27abc & 48.8abcd & 39.5abcd & 28.3abc \\
\hline TNM 9 & 51.5ab & 52.8ab & 49.87abc & 43.9abcdefg & 41.9abcd & 35.5ab \\
\hline CML504 & 51.4ab & 50.5abc & 52.5abc & 50.1abc & 48.7ab & 30.0abc \\
\hline CML206 & 51.3ab & 46.7bc & 44.5bc & 43.3abcdef & 40.0abcd & 29.7abc \\
\hline CML509 & 50.6ab & 49.3abc & 49.7abc & 45.2abcdef & 43.8abc & 35.6ab \\
\hline CML144 & $50.4 \mathrm{ab}$ & $50.5 \mathrm{abc}$ & $41.2 \mathrm{c}$ & 40.3abcdefg & 34.7abc & 24.1abc \\
\hline CML444 & $50.0 \mathrm{ab}$ & $39.8 c$ & $41.3 c$ & 33.3fg & $29.6 \mathrm{~cd}$ & 27.3abc \\
\hline CML202 & 49.9ab & 54.6ab & $52.2 \mathrm{abc}$ & 51.3ab & 43.0abc & 37.3ab \\
\hline CML387 & 49.9ab & $55.2 \mathrm{ab}$ & $59.9 a$ & 48.9abcd & 42.7abc & $34.0 \mathrm{bc}$ \\
\hline CML465 & 49.6ab & 48.4abc & 45.9ab & 40.2abcdefg & 36.5abc & 25.4abc \\
\hline CML176 & 49.4ab & $50.7 \mathrm{abc}$ & 44.3bc & 41.9abcdefg & 38.6abcd & 28.5abc \\
\hline CML254 & 49.3ab & 48.4abc & 44.7ab & 37.3cdefg & 34.0abc & 23.9abc \\
\hline CML511 & 49.0ab & 50.9ab & 49.6abc & 46.1abcdef & 43.3abc & $40.0 \mathrm{a}$ \\
\hline CML470 & 49.9ab & 49.6abc & 48.6abc & 43.1abcdefg & 34.5abc & 32.3ab \\
\hline TNM 7 & 48.5ab & 51.7ab & 45.7ab & 43.2abcdefg & $45.2 \mathrm{abc}$ & 32.2ab \\
\hline CML251 & 46.9ab & 51.9ab & 54.4abc & 46.3abcdef & 43.2anc & 32.7ab \\
\hline CML163 & 46.7ab & 47.9abc & 43.9bc & 37.0cdefg & 34.0abc & 23.7abc \\
\hline CML451 & 46.5ab & $51.2 \mathrm{ab}$ & 48.0abc & 47.3abcde & 41.1abcd & 31.7abc \\
\hline CML264 & 46.4ab & $51.7 \mathrm{ab}$ & $50.8 \mathrm{abc}$ & 49.2abc & 41.9abcd & 34.6ab \\
\hline CML247 & $46.4 \mathrm{a}$ & 49.7abc & 53.5abc & 42.0abcdefg & 46.9ab & 38.8ab \\
\hline TNM 6 & 46.1b & $54.2 \mathrm{ab}$ & 52.7abc & 44.7abcdef & 48.2ab & 39.3ab \\
\hline CML161 & $45.3 b$ & 47.4abc & 48.9abc & 43.9abcdefg & 40.4abcd & 26.2abc \\
\hline CML395 & $44.9 b$ & $44.2 \mathrm{bc}$ & $42.1 \mathrm{c}$ & 35.5defg & 33.0abc & 28.1abc \\
\hline CML216 & $44.6 \mathrm{~b}$ & 51.1ab & 50.8abc & 49.6abc & 40.6abcd & 30.8abc \\
\hline CML448 & $44.1 \mathrm{~b}$ & $44.6 \mathrm{bc}$ & $40.9 \mathrm{c}$ & 35.2efg & $35.5 a b c$ & 29.6abc \\
\hline
\end{tabular}

V6 = sixth leaf stage, VT = flowering stage, R3 = milk stage, R4 = doughy stage, R5 = dented stage, and PM = physiological maturity. 
since the lines contained and produced the highest concentration of chlorophyll in the R4 and R5 stages; the early date showed better results than the late date (June).

There were also lines that did not exceed 51 SPAD units, particularly in the R4 and R5 stages, despite belonging to the first statistical group; therefore, these lines do not have a high yield potential, although they cannot be completely discarded. Figure 1 shows the variation between the 36 lines; five major groups were formed according to chlorophyll concentration in the six phenological stages. This indicates that the lines belonging to each group are similar despite coming from different environments and showing different precocity. The first group consisted of three lines, CML 312, CML 505 and CML 496, with SPAD values ranging from 44.51 to 47.46 and an average of 45.90. The second group was formed by 10 lines: CML 491 TNM 9, CML 509, CML 511, TNM 7, CML 202, CML 251, CML 451, CML 216 and CML 264, which had SPAD values from 44.36 to 48.10, with an average 45.93. The third and fourth groups were formed by two lines each: CML 247, TNM 6 and TNM 8, CML 504, respectively; they showed an average of 46.90 and 46.77 SPAD units, respectively. The fifth group was formed by the CML 387 line, with an average of 48.48 SPAD units, while the sixth group was formed by 13 lines: CML 376, CML 206, CML 465, CML 176, CML 161, CML 311, CML 456, CML 470, CML 159, CML 287, CML 144, CML 254 and CML 163, with an average of 41.24 SPAD units. The seventh group was formed by three lines CML 444, CML 395 and CML 448, ranging from 36.92 to 38.37 and with an average of 37.77 SPAD units. Finally, the eighth group was formed by two lines: CML 197 and CML 421, with an average of 45.33 SPAD units. The information generated by the grouping allowed us to identify the more compact groups in terms of their similarity in SPAD values; similar lines could be used in hybrid combinations in a genetic improvement program [18].

The dispersion of the 14 agronomic characteristics of the 36 inbred lines can be seen in Figure 2, where the main components, 1 (2.31\%) and 2 (3.77\%), accounted for $6.08 \%$ of the phenotypic variation observed in the 36 lines. According to the eigenvectors, the variables with more weight in the first factor were: $\mathrm{PH}, \mathrm{CH}, \mathrm{LBC}, \mathrm{FF}$, MF, PM, P100, CL, DC, CC and GY. In the second factor, the most important variables were: LAC, KR and RC. Considering all 36 lines, we observed that plant height ranged from 1.48 to $1.92 \mathrm{~m}$, with as average of $1.71 \mathrm{~m}$; corn cob height ranged from 0.63 to $0.91 \mathrm{~m}$, with an average of $0.77 \mathrm{~m}$.

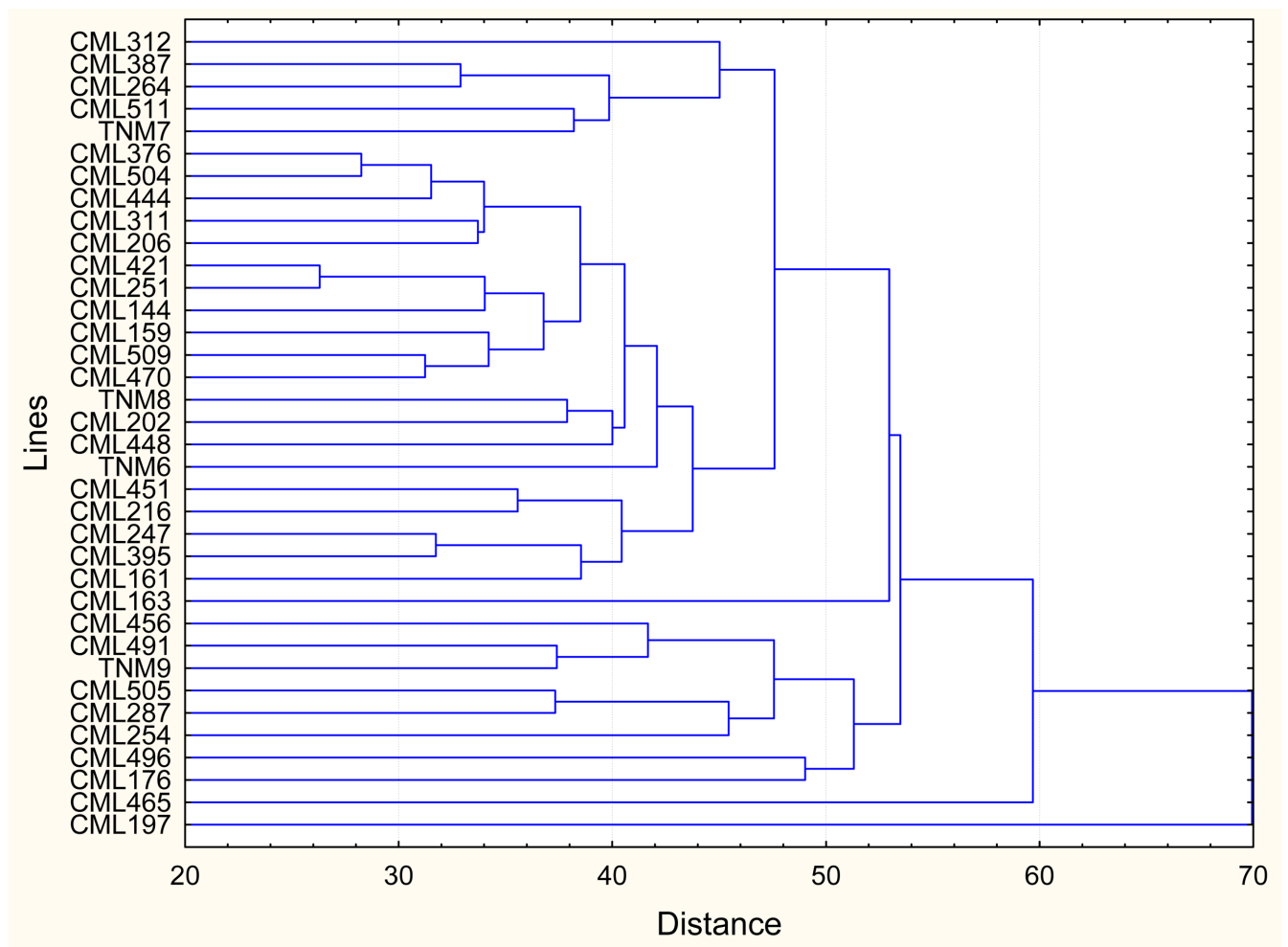

Figure 1. Dendrogram generated from the SPAD units of 36 inbred lines of corn at six phenological stages and two planting dates; obtained with the UPGMA method. 


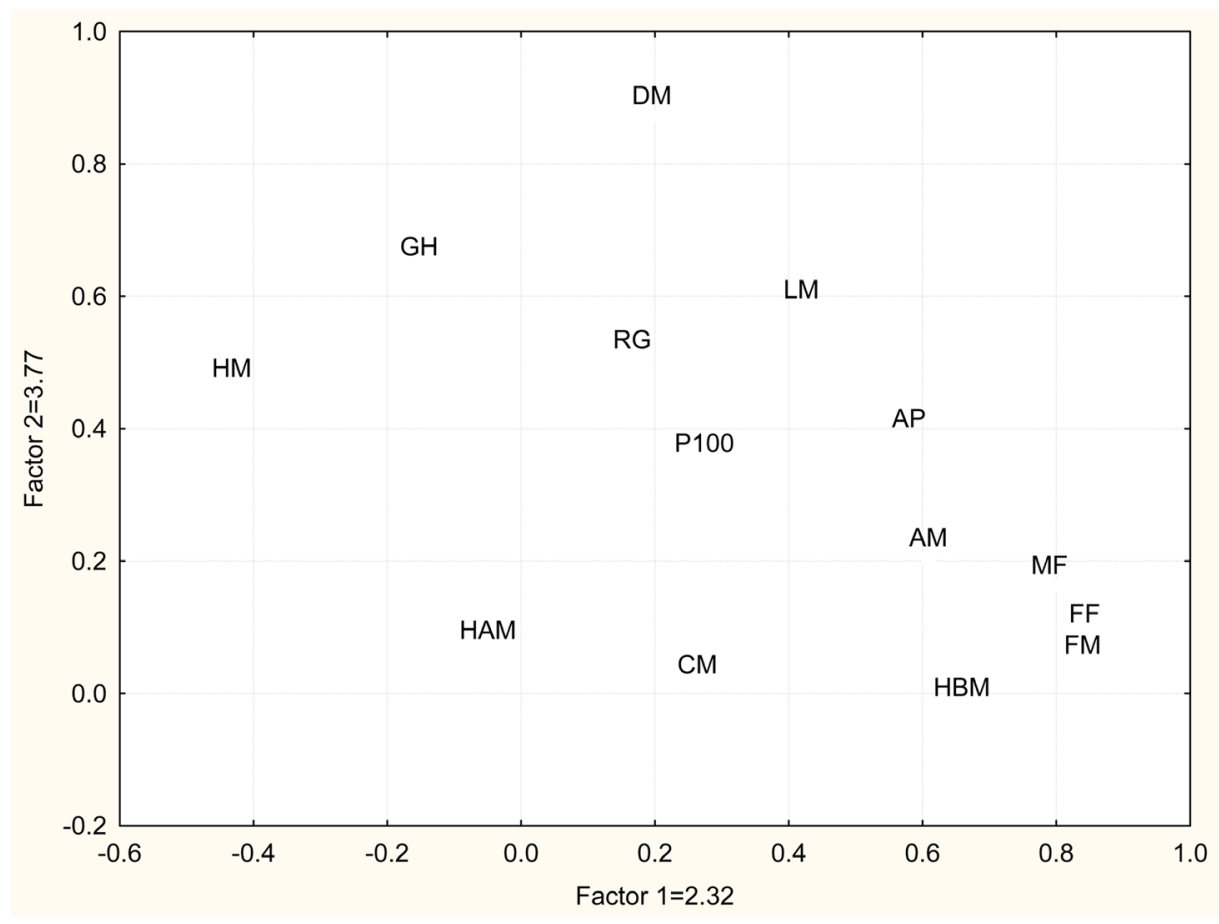

Figure 2. Dispersion of the 14 agronomic characteristics of the 36 inbred lines in the mean plane determined by the main components.

The variable of the number of leaves above the cob was higher than that of leaves below the cob, with an average of 7.13. Flowering was more precocious in the first date, which is explained because the temperatures in March were above $28^{\circ} \mathrm{C}$, while the temperatures declined in June. Female flowering, male flowering, physiological maturity and cob diameter showed a positive association with $0.84,0.83,0.79$ and 0.87 respectively. With respect to cob length, rows per cob, kernels per row, weight of 100 seeds and grain yield, there were on average higher values on the first date. These results show the genetic diversity of the 36 lines in terms of appearance, health of plant and cob, precocity and yield. This variability is attributable to the selection and identification of germplasm, which could thus be used as a criterion for a future genetic improvement program [18]. The cluster analysis for agronomic characteristics detected eight groups, which were formed with 5, 11.4, 5, 1.6, 2.1, and 1, respectively. The first group was formed by lines CML312 of subtropical origin with intermediate maturity cycle, CML387 subtropical-late, CML264 tropical-intermediate, CML511tropical-intermediate and TNM 7 subtropical-intermediate. The second group was 63.63\% tropical, with the lines CML 504, CML 421, CML 251, CML 144, CML 159, CML 509 and CML 470, two lines of late maturing, three intermediate and two early. The CML 421 and CML 470 lines seem to be particularly excellent choices as a source of resistance to drought under these environmental conditions, in which the lines in question can be used for the production of hybrids. This is why they should be considered for use in genetic improvement programs by researchers aware of the variability of rain in rain fed agriculture.

The lines of the third group were $36.37 \%$ of subtropical origin, including CML 376 with intermediate maturity cycle, CML 444 late cycle, CML 311 late cycle and CML 206 late cycle. The third group was formed by four lines: TNM 8 of subtropical origin and intermediate maturity cycle, CML 202 subtropical-late, CML-448 tropical-late and TNM 6 subtropical-intermediate. The fourth group was formed by five lines with late cycle, $60 \%$ of tropical origin, CML 451, CML 247 and CML 161, and 40\% of subtropical origin, CML 216 and CML 395. The fifth group was formed by line CML 163 tropical-late. The sixth group was formed by six lines, five of tropical origin: CML 456 and CML 491 with late cycle, CML 505, CML 287 and CML 254 intermediate, and the TNM 9 line of subtropical origin and intermediate cycle. The seventh group included CML 496 tropical-intermediate and CML 176 subtropical-intermediate. The eighth group comprised a single line, CML 465 tropical, while the ninth group was formed by CML 197 subtropical-intermediate. These results show the variability and genetic similarity of in the lines within each group and between the groups formed according to the characterization of 
the agronomic variables.

The classification of the lines according to different planting dates and contrasting maturity cycles will help create a more effective genetic improvement program, that is, less time-consuming and less costly. This is consistent with the results of [22], who reported the importance of identifying promising genetic material when performing a morphological characterization, as they did in 52 populations, concluding that the maturity cycle and the environment of the genetic materials are very important for differentiating them into groups and conducting a genetic improvement program. Moreover, [18] performed a morphological characterization of corn lines and concluded that clusters allow to identify lines from different environments and different maturity cycles, which can help conduct a more efficient genetic improvement program and obtain materials with a greater range of adaptation. The main components allowed to group agronomic characteristics into two major vectors.

\section{Conclusion}

We identified 18 lines with the highest chlorophyll content (above 51 SPAD units), the best for obtaining hybrids with a high yield potential. In the V6 stage, the line with the highest chlorophyll content was CML 312, with 57.66 SPAD units; in the flowering, R4, R5 and R6 stages, the CML 197 line had the highest chlorophyll content, with 58.45, 53.72, 54.15 and 41.38 SPAD units, respectively. In the R3 stage, the CML 387 line was the one with the highest chlorophyll content, with 59.91 SPAD units. We also identified lines with low concentrations of chlorophyll in each vegetative stage: CML 448, CML 444, CML 448, CML 287 and CML 421, with 44.15, 39.80, 40.96, 32.32, 25.30 and 12.57 SPAD units, respectively; the last two values corresponded to the genotype CML 421. We formed 7 groups of corn lines according to the concentration of chlorophyll and eight according to the agronomic characteristics; this helped identify common groups for a hybridization program.

\section{References}

[1] Cao, M.J., Yu, H.Q. and Yan, H.K. (2007) Difference in Tolerance to Potassium Deficiency between Two Maize Inbred Lines. Plant Production Science, 10, 42-46. http://dx.doi.org/10.1626/pps.10.42

[2] Marschner, H. and Marschner, P. (2011) Marschner’s Mineral Nutrition of Higher Plants. Elsevier, London.

[3] Pettigrew, W.T. (2008) Potassium Influences on Yield and Quality Production for Maize, Wheat, Soybean and Cotton. Physiologia Plantarum, 133, 670-681. http://dx.doi.org/10.1111/j.1399-3054.2008.01073.x

[4] Jin, J.Y. (2012) Changes in the Efficiency of Fertiliser Use in China. Journal of the Science of Food and Agriculture, 92, 1006-1009.

[5] Gentinetta, E., Ceppi, D., Perico, G., Motto, M. and Salamini, F.A. (1986) Major Gene for Delayed Senescence in Maize: Pattern of Photosynthates Accumulation and Inheritance. Plant Breeding, 97, 193-203. http://dx.doi.org/10.1111/j.1439-0523.1986.tb01053.x

[6] Stefan, H. (2009) Stay-Green Regulates Chlorophyll and Chlorophyll-Binding Protein Degradation during Senescence. Trends in Plant Science, 14, 155-162. http://dx.doi.org/10.1016/j.tplants.2009.01.002

[7] Etsushi, K., Ken, J.I., Satoshi, U., Keiichi, O., Cevayir, C. and Shizuo, A. (2011) Silica Crystals and Aluminum Salts Regulate the Production of Prostaglandin in Macrophages via NALP3 Inflammasome-Independent Mechanisms. Immunity, 34, 514-526. http://dx.doi.org/10.1016/j.immuni.2011.03.019

[8] Haldimann, P., Fracheboud, Y. and Stamp, P. (1996) Photosynthetic Performance and Resistance to Photoinhibition of Zea mays L. Leaves Grown at Suboptimal Temperature. Plant, Cell and Environment, 19, 85-92. http://dx.doi.org/10.1111/j.1365-3040.1996.tb00229.x

[9] Wang, X.G., Zhao, X.H., Jiang, C.J., Li, C.H., Cong, S., Wu, D., Chen, Y.Q., Yu, H.Q. and Wang, C.Y. (2015) Effects of Potassium Deficiency on Photosynthesis and Photoprotection Mechanisms in Soybean (Glycine max (L.) Merr.).Journal of Integrative Agriculture, 14, 856-863. http://dx.doi.org/10.1016/S2095-3119(14)60848-0

[10] Haochuan, L., Jihua, T., Yanmin, H.V., Jiwey, Y. and Zonghua, L. (2014) Analysis on Combing Ability and Estimation of Genetic Parameter for Clorophyllconten in Maize. Journal of Plant Breeding and Crop Science, 6, 97:104.

[11] Ángeles, G.E., Ortiz, E.T., López, P.A. and López, G.R. (2010) Characterization and Performance of Populations of Native Corn Molcaxac, Puebla. Revista Fitotecnia Mexicana, 33, 287-296.

[12] Zotarelli, L., García, C., Piccinin, J.L., Urquiaga, S., Boddey, R.M., Torres, E. and Rodríguez, B.J. (2003) Calibração do medidor de clorofila minolta SPAD 502 para avaliação du conteúdo de nitrogênio do milho. Pesquisa Agropecuária Brasileira, 38, 1117-1122. http://dx.doi.org/10.1590/S0100-204X2003000900014 
[13] Caires, N.O.S., de Carvalo, G.J.D.., Pereira, M.F.A. and Pinho, T.R. (2005) Uso do SPAD 502 naavaliação dos teores foliares de clorofila, nitrogênio, enxofre, ferro e manganês do algodoneira herbáceo.

[14] Gold, M.M. (2001) Energy Processes of Life: Photosynthesis. 3a Print. Editorial UNAM, Institute of Geography, Mexico D.F., 245 p.

[15] Fageria, N.K. (2009) The Use of Nutrients in Crop Plants. CRC Press, Boca Raton.

[16] Jiang, C.C., Chen, F., Gao, X.Z., Lu, J.W., Wan, K.Y., Nian, F.Z. and Wang, Y.H. (2008) Study on the Nutrition Characteristics of Different K Use Efficiency Cotton Genotypes to K Deficiency Stress. Agricultural Science in China, 7, 740-745. http://dx.doi.org/10.1016/S1671-2927(08)60109-1

[17] Peterson, R.B., Oja, V. and Laisk, A. (2001) Chlorophyll Fluorescence at 680 and $730 \mathrm{~nm}$ and Leaf Photosynthesis. Photosynthesis Research, 70, 185-196. http://dx.doi.org/10.1023/A:1017952500015

[18] Rodríguez, PG., Zavala, F.G., Ojeda, C.Z., Gutiérrez, A.D., Treviño, J.E.R. and Rincón, F.S. (2012) Diversity of Landraces of Nuevo Leon, Mexico, by AFLP and Morphological Characters. Mesoamerican Agriculture, 23, 29.39.

[19] Liu, J.C., Li, J.S., Mi, G.H., Chen, F.J. and Zhang, F.S. (2009) QTL Mapping of Seedling Growth Traits and Grain Yield under Two Nitrogen Conditions in Maize. Scientia Agricultura Sinica, 42, 3413-3420. (In Chinese)

[20] Osório, J., Osório, M.L., Correia, P.J., de Varennes, A. and Pestana, M. (2014) Chlorophyll Fluorescence Imaging as aTool to Understand the Impact of Iron Deficiency and Resupply on Photosynthetic Performance of Strawberry Plants. Scientia Horticulturae, 165, 148-155. http://dx.doi.org/10.1016/j.scienta.2013.10.042

[21] D’Hooghe, P., Escamez, S., Trouverie, J. and Avice, J.C. (2013) Sulphur Limitation Provokes Physiological and Leaf Proteome Changes in Oilseed Rape That Lead to Perturbation of Sulphur, Carbon and Oxidative Metabolisms. BMC. Plant Biology, 13, 23. http://dx.doi.org/10.1186/1471-2229-13-23

[22] Gregersen, P.L., Culetic, A., Boschian, L. and Krupinska, K. (2013) Plant Senescence and Crop Productivity. PlantMolecular Biology, 82, 603-622. http://dx.doi.org/10.1007/s11103-013-0013-8 